\title{
Expression profile of tuberin and some potential tumorigenic factors in 60 patients with uterine leiomyomata
}

\author{
Jianjun Wei ${ }^{1}$, Luis Chiriboga ${ }^{1}$, Masashi Mizuguchi ${ }^{2},{\text { Herman } \text { Yee }^{1} \text { and Khush Mittal }}^{1}$ \\ ${ }^{1}$ Department of Pathology, New York University School of Medicine, New York, NY, USA and ${ }^{2}$ Department of \\ Pediatrics, Jichi Medical School, Kawachi-gun, Tochigi, Japan
}

\begin{abstract}
Human uterine leiomyomata are the most common tumors in women of reproductive age. The pathogenesis of leiomyomata remains unknown. An animal model of Eker rats with deleted tuberous sclerosis complex gene 2 (tuberin) shows increased incidence of leiomyomata. The role of tuberin in human leiomyomata is unknown. In this study, we designed a tissue microarray with tissue cores of leiomyomata and the matched myometrium from 60 hysterectomy specimens. We examined the expression of tuberin and tuberous sclerosis complex gene 1 product hamartin, proteins of the insulin-signaling pathway, steroid receptors and some of their cofactors, and human mobility group gene A2 by immunohistochemistry. We found that nearly half of the cases displayed either reduction or loss of tuberin in leiomyomata compared with matched normal myometrium. No change of hamartin was noted. Furthermore, a significant reduction of glucocorticoid receptor was found in leiomyomata with reduced tuberin. The proteins insulin like growth factor 1 , insulin-like growth factor receptor $\beta$, AKT kinase, and phosphatidylinositol 3-kinase were upregulated. Nearly half of leiomyomata show upregulation of human mobility group gene A2, along with the steroid receptor cofactors. Our findings suggest that there are two broad groups of uterine leiomyomata. One group is associated with an alteration of tuberin and glucocorticoid receptor. The other group is associated with upregulation of human mobility group gene A2 and steroid receptor cofactors.
\end{abstract}

Modern Pathology (2005) 18, 179-188, advance online publication, 1 October 2004; doi:10.1038/modpathol.3800283

Keywords: cluster analysis; high-mobility group protein gene A2; insulin-signaling pathway; steroid hormone receptors; steroid hormone receptor cofactors; tissue microarray; tuberous sclerosis complex proteins; uterine leiomyomata

The pathogenesis of leiomyomata has been pursued in many studies. The factors related to tumorigenesis of leiomyomata can be categorized as risk factors, initiators, promoters, and effectors. ${ }^{1}$ The causes of leiomyomata (initiators) remain unknown. Most identified leiomyomata-associated factors, such as local growth factors, ER, PR and nonrandom chromosomal alterations were considered to be promoters or effectors. ${ }^{1}$ Some growth factors have been shown to be overexpressed in leiomyomata, and are hormonally regulated both in vivo and in vitro. These factors are either autocrine or paracrine, which promote mitogenic and fibrogenic action in these tissues. ${ }^{2}$ Nonrandom chromosomal abnormalities are found in up to $40 \%$ of leiomyomata. ${ }^{3,4}$ The

Correspondence: Dr K Mittal, MD, Department of Pathology, Bellevue Hospital, Room 4W1, 462 First Avenue, New York, NY 10016, USA.

E-mail: khush.mittal@med.nyu.edu

Received 1 June 2004; revised 12 August 2004; accepted 16 August 2004; published online 1 October 2004 high-mobility group protein genes are considered candidate genes for leiomyomata as these were identified from breakpoints of chromosomal translocation in leiomyomata. ${ }^{3,5}$ Although an upregulation of high-mobility group protein gene A2 has been found in some leiomyomata, ${ }^{5,6}$ the fusion highmobility group protein gene A2 by truncated transcripts at translocation breakpoints is not a common molecular event. ${ }^{7}$ Gene chip studies have provided a means of identifying differentially expressed genes in leiomyomata. ${ }^{8-10}$ A group of genes have been found either up- or downregulated in leiomyomata. None of them has been linked to the pathogenesis of the leiomyomata.

A mutation of fumarate hydratase has been identified in the rare entity of the familial cutaneous and uterine leiomyomas. ${ }^{11}$ Mutations of fumarate hydratase in the common type of human leiomyomata have been found occasionally. An animal model of leiomyomata has been developed in Eker rats, in which, a germline mutation of tuberous sclerosis gene 2 was introduced. ${ }^{12,13}$ The Eker rats 
develop spontaneous leiomyomata at a high frequency $(65 \%)$ and the tumors are histologically identical to typical human leiomyomata. Hunter et $a l^{14}$ reported loss or reduction of tuberous sclerosis gene-2 product tuberin in Eker rat leiomyomata. This is the first report showing a loss of the tumor suppressor tuberin in leiomyomas.

The genes of tuberous sclerosis complex encode the tumor suppressor proteins hamartin (tuberous sclerosis gene 1) and tuberin (tuberous sclerosis gene 2) that are broadly expressed in many organs and tissues including myometrium and most smooth muscle tissues. ${ }^{15}$ They normally inhibit cell proliferation by a negative regulation of the cell cycle and in part through the insulin receptor signal pathway. ${ }^{16,17}$ Inactivation of either tuberous sclerosis gene 2 or tuberous sclerosis gene 1 genes leads to the formation of mostly benign neoplasms in patients with tuberous sclerosis complex. ${ }^{18-20}$ The association between alteration of tuberous sclerosis complex genes and incidence of human uterine leiomyomas is unknown. This may be partly due to a high incidence of the tumor in both the general population and tuberous sclerosis complex patients. In this study, we designed a tissue microarray for immunohistochemistry to examine the expression of tuberous sclerosis complex gene products in human leiomyomata. Other selected proteins of potential significance in the pathogenesis of leiomyomata were also investigated.

\section{Materials and methods}

\section{Specimen Collection}

Archival formalin-fixed, paraffin-embedded specimens with uterine leiomyomata were collected from 60 patients who underwent hysterectomy at the New York University Hospitals Center during 2001 and 2002. A pathological diagnosis of uterine leiomyomata was made on each case. Unusual subtypes of leiomyomata were not included in this study. Cases with a history of malignancy of the reproductive system were excluded. Patient ages ranged from 37 to 82 years with the mean age of 49.2 years. Tumor sizes spanned from 1.5 to $19 \mathrm{~cm}$ with an average of $5.77 \mathrm{~cm}$. Sections from myometrium and myomas were reviewed and those with viable tumors were selected for the study.

\section{Tissue Array}

From each specimen, four 0.6-mm. diameter tissue cores were collected, two from normal myometrium and two from leiomyoma of each specimen. A total of 240 tissue cores were arrayed into two blocks. Tissues from normal fetal adrenal, endometrium and breast carcinoma were selected as immunohistochemical controls.

\section{Antibody Panels}

Antibody panels were designed to demonstrate the following proteins: (1) tuberous sclerosis complex gene products: hamartin and tuberin; (2) insulinsignaling pathway: insulin-like growth factor 1 , insulin-like growth factor receptor $\beta$, epidermal growth factor receptor, phosphatidylinositol 3-kinase, and AKT kinase; (3) steroid hormone receptors: estrogen receptor, progesterone receptor, glucocorticoid receptor and their coactivators: steroid receptor cofactor 1 , amplified in breast cancer 1 and glucocorticoid receptor interacting protein 1; (4) cell proliferation and other control markers: c-Kit, cyclin D1, CD24, Her2/neu, high mobility group protein gene A2, Ki-67, P27 and smooth muscle actin (Table 1).

\section{Hamartin and tuberin}

Antibodies to hamartin were raised by immunizing rabbits against two peptides synthesized according to the sequence deduced from human tuberous sclerosis gene $1 \mathrm{cDNA}$. The first peptide consisted of hamartin amino-acid residues 231-245 plus the carboxy-terminal cysteine (peptide Hamartin-N: PELVTGSKDHELDPRC). The second peptide was composed of residues 1150-1164 plus the aminoterminal cysteine (peptide Hamartin-C: CQLHIMDYNETHHEHS). Antibody to tuberin was raised in rabbits against a peptide synthesized according to the sequence deduced from human tuberous sclerosis gene 2 cDNA. This consisted of amino-acid residues 1770-1784 plus the amino-terminal cysteine (peptide Tuberin: CRKRLISSVEDFTEFV), corresponding to the carboxy terminal of tuberin. Peptide synthesis, immunization, collection, and absorption of the antisera were performed as previously described..$^{21-23}$ Antibody specificity was determined by Western blot and negative control experiments with preabsorbed antisera.

\section{Other antibodies}

All other antibodies were obtained from commercial sources. The manufacturers and working dilutions for each antibody are summarized in Table 1.

\section{Immunohistochemistry}

Both paraffin-embedded tissue array blocks were sectioned at $4 \mu \mathrm{m}$. Sections were collected from each block and placed onto the same slide, heated for $30 \mathrm{~min}$ in a convection oven and then, deparaffinized in xylene, dehydrated in graded alcohol and rinsed in distilled water. Antigen retrieval was performed by either heat-induced epitope retrieval $(0.01 \mathrm{M}$ citric acid buffer ( $\mathrm{pH} 6.0)$ in a $1200 \mathrm{~W}$ microwave oven) or by proteolytic enzyme digestion. All immunohistochemical staining was performed on a Ventana Nexus automated system (Tucson, AZ, USA). In brief, following antigen 
Table 1 Antibody names, titers and sources

\begin{tabular}{|c|c|c|c|}
\hline Markers & Panel & Vendor/source & Titer \\
\hline Hamartin-C & A & Mizuguchi M & $1: 500$ \\
\hline Hamartin-N & A & Mizuguchi M & $1: 300$ \\
\hline Tuberin & A & Mizuguchi M & $1: 700$ \\
\hline Insulin like growth factor 1 & $\mathrm{~B}$ & Neo Markers & $1: 20$ \\
\hline Insulin-like growth factor receptor $\beta$ & $\mathrm{B}$ & Santa Cruz & $1: 50$ \\
\hline Phosphatidylinositol 3-kinase & $\mathrm{B}$ & Santa Cruz & $1: 80$ \\
\hline PTEN & $\mathrm{B}$ & NovoCastra & $1: 20$ \\
\hline AKT kinase & $\mathrm{B}$ & Cell Signaling & $1: 20$ \\
\hline Glucocorticoid receptor & $\mathrm{C}$ & NovoCastra & $1: 50$ \\
\hline Estrogen receptor & $\mathrm{C}$ & Ventana Medical Systems & Neat \\
\hline Progesterone receptor & $\mathrm{C}$ & Ventana Medical Systems & Neat \\
\hline Steroid receptor cofactor 1 & $\mathrm{C}$ & Affinity BioReagents & $1: 20$ \\
\hline Glucocorticoid receptor interacting protein 1 & $\mathrm{C}$ & Affinity BioReagents & $1: 100$ \\
\hline Amplified in breast cancer 1 & $\mathrm{C}$ & Affinity BioReagents & $1: 20$ \\
\hline Epidermal growth factor receptor & $\mathrm{D}$ & Zymed & $1: 20$ \\
\hline $\mathrm{Ki}-67$ & $\mathrm{D}$ & Ventana Medical Systems & Neat \\
\hline Smooth muscle actin & $\mathrm{D}$ & Dako & Neat \\
\hline High-mobility group protein gene A2 & $\mathrm{D}$ & Babco & $1: 200$ \\
\hline c-kit & $\mathrm{D}$ & Calbiochem & $1: 100$ \\
\hline p27 & $\mathrm{D}$ & Santa Cruz & $1: 20$ \\
\hline Cyclin D1 & $\mathrm{D}$ & Zymed & $1: 10$ \\
\hline CD24 & $\mathrm{D}$ & Neomarkers & $1: 25$ \\
\hline Her2/neu & $\mathrm{D}$ & Ventana Medical Systems & Neat \\
\hline
\end{tabular}

retrieval, endogenous peroxidase activity was blocked with $3 \%$ hydrogen peroxide. Primary antibodies were detected using standard biotinylated anti-mouse or anti-rabbit secondary antibodies. This was followed by application of streptavidin-horseradish-peroxidase conjugate. The complex was visualized by the enzymatic oxidation of DAB $\left(3,3^{\prime}\right.$ diamanobenzidine tetrahydrochloride) substrate and enhanced with copper sulfate.

\section{Data Analysis and Scoring for Immunodensity}

The following steps were taken to minimize histological and immunohistochemical technique bias in preparation for semiquantitative analysis of the immunomarkers: (1) Paired tissue cores from the normal myometrium and leiomyomas were selected and placed side by side and all 240 tissue cores from two tissue blocks were placed on single slide to minimize variation of the immunohistochemical staining. (2) The research antibodies hamartin, tuberin, insulin-like growth factor receptor, glucocorticoid receptor, AKT kinase, phosphatidylinositol 3-kinase, CD24, steroid receptor cofactor 1, glucocorticoid receptor interacting protein 1, amplified in breast cancer 1 and high-mobility group protein gene A2 were tested in multiple tissues to optimize antigen retrieval and antibody titer (Table 1). Staining conditions for antibodies against estrogen receptor, progesterone receptor, Her2/neu, p27, smooth muscle actin, Ki-67, and Cyclin D1 followed protocols recommended by the manufactures. (3) Experiments were performed in duplicate to obtain comparable patterns for the markers. (4) Immunoreactivity was graded by two pathologists with a visual semiquantitation (optical density of the immunoreactivity) according to the following scale: 0 (negative), 0.5 (faint), 1 (weak), 2 (moderate) and 3 (strong). Quantitative $\mathrm{H}$ score $(\mathrm{QH})$ was used for estrogen receptor, progesterone receptor and glucocorticoid receptor based on Nisolle et al. ${ }^{24} \mathrm{QH}=\sum P i$ ( $i$ is optical density $0-4, P$ is the percentage of positive cells in each given $i$ ). $P$-value was calculated by the $t$-test. $P$-values less than 0.05 were counted as significant.

\section{Unsupervised Hierarchal Cluster Analysis}

Raw tissue microarray immunohistochemical scores were processed into pre-cluster format using the tissue microarray deconvoluter (freeware available at http://genome-www.stanford.edu/TMA). ${ }^{25}$ Data were clustered using Cluster and the output (clusters and dendrograms) visualized with Treeview (freeware available at http://rana.lbl.gov/) software originally designed for analyzing cDNA microarray data. ${ }^{26}$ In brief, immunohistochemical raw scores were modified using the TMA deconvoluter by multiplying each score by the absolute value of itself and then converting the scores symmetrically about zero. This increases the magnitude of the large differences among scored samples while minimizing small differences that may not be significant due to the qualitative nature of immunohistochemical scoring. The deconvolved results were then prefiltered by eliminating scores in which the absolute, maximum minus minimum value was less than 0.25. Distances were calculated using an uncentered Pearson's correlation metric, and then clustered by the average linkage method. ${ }^{26}$ Age was scored by 
setting the mean to zero and then scaling the data into intervals that corresponded to our original scoring system. For age data, this produces a 5-year interval (from 30 to 66 years of age) scoring scale with a high-low cutoff of greater than 66 years and less than 30 years of age. The scored, age data for all samples were then incorporated into the original data set. The combined data were then deconvolved and clustered as above. The entire data set was used for clustering unless otherwise specified.

\section{Results}

\section{Tissue Array and Pathology Findings}

A concerted effort was made to minimize variation between cases due to specimen preparation and handling. The case-matched myometrium was used as an internal control. The differential expression for each marker protein was evaluated by the semiquantitation of the immunohistochemistry between leiomyomata and normal myometrium. Both the leiomyomata and myometrium showed diffuse positive staining for smooth muscle actin in all cores, indicating preservation of tissue antigens. Leiomyomata showed higher Ki-67 expression than myometrium, as expected.

\section{Immunohistochemical Data in the Panels}

The gene products examined in our study were subdivided into four panels based on their different functions and potential role in leiomyomata. Panel A includes tuberin and hamartin, which are the gene products of tuberous sclerosis complex. Panel $\mathrm{B}$ includes insulin-like growth factor 1, insulin-like growth factor receptor $\beta$, epidermal growth factor receptor, phosphatidylinositol 3-kinase and AKT kinase. These proteins from insulin-signaling pathway are associated with the function of tuberin and hamartin. ${ }^{16,27}$ Panel $C$ includes estrogen receptor, progesterone receptor, glucocorticoid receptor and their cofactors steroid receptor cofactor 1, amplified in breast cancer 1 and glucocorticoid receptor interacting protein 1. Panel D includes markers for cell proliferation (Ki-67, p27, cyclin D1), tumorigenesis (high-mobility group protein gene A2, c-kit, Her2/neu, CD24) and control (smooth muscle actin). Immunostains were counted only in those cases with well-sectioned tissue cores for both control and tumor. The average scores for each of the antibodies in the leiomyomata and their differences from the normal myometrium are summarized in Table 2 and shown in Figures 1 and 2.

Panel A: The normal myometrium showed weak to moderate immunoreactivity for tuberin $(+$ to + + intensity) with a diffuse cytoplasmic distribution. Differential expression of tuberin, between myometrium and leiomyomata was identified in 29 out of 54 cases $(53.7 \%)$. Nine cases showed loss of immunoreactivity for tuberin in leiomyomata. The differential expression of tuberin between normal myometrium (average score of immunoreactivity $=$ 0.99 ) and leiomyomata (score $=0.64$ ) was significant $(P<0.001)$ (Figure 2 and Table 2). Immunoreactivity for hamartin was weak to moderate with a diffuse staining pattern in the cytoplasm of all myometrium and leiomyomata. Variation in the immunoreactivity for hamartin between cases was small. No significant increase of immunoreactivity for hamartin was noted in leiomyomata. A comparison of the aminoterminal and carboxy-terminal hamartin-specific antibodies showed similar results.

Panel B: Insulin-signaling pathway involves proteins that control cell proliferation and differentiation. Recent studies provide increasing evidence of

Table 2 Immunoreactivity for various markers in the uterine leiomyomata and normal myometrium

\begin{tabular}{|c|c|c|c|c|c|c|c|}
\hline \multirow[t]{2}{*}{ Markers } & \multirow[t]{2}{*}{ Panel } & \multirow[t]{2}{*}{ No. cases $^{\mathrm{a}}$} & \multicolumn{2}{|c|}{ Leiomyomata } & \multicolumn{2}{|c|}{ Myometrium } & \multirow[t]{2}{*}{ P-value } \\
\hline & & & Mean & s.d. & Mean & s.d. & \\
\hline Tuberin & A & 54 & 0.644231 & 0.042228 & 0.995327 & 0.044576 & $5.25 \mathrm{E}-08$ \\
\hline Hamartin & A & 54 & 0.754717 & 0.045366 & 0.721698 & 0.040623 & 0.589999 \\
\hline Phosphatidylinositol 3-kinase & B & 54 & 0.717374 & 0.053359 & 0.542933 & 0.049989 & 0.084125 \\
\hline AKT kinase & B & 53 & 0.941767 & 0.041201 & 0.835554 & 0.042245 & 0.315237 \\
\hline Insulin-like growth factor receptor $\beta$ & B & 52 & 1.174757 & 0.054798 & 1.029126 & 0.043326 & 0.039273 \\
\hline Insulin-like growth factor 1 & B & 56 & 1.238739 & 0.055482 & 0.968468 & 0.047365 & 0.000285 \\
\hline Glucocorticoid receptor & $\mathrm{C}$ & 55 & 0.363636 & 0.041922 & 1.077273 & 0.046232 & $1.04 \mathrm{E}-23$ \\
\hline Estrogen receptor & $\mathrm{C}$ & 51 & 1.005007 & 0.069123 & 1.217822 & 0.069103 & 0.031865 \\
\hline Progesterone receptor & $\mathrm{C}$ & 55 & 1.444954 & 0.06466 & 1.634259 & 0.059238 & 0.033197 \\
\hline Amplified in breast cancer 1 & $\mathrm{C}$ & 56 & 1.991071 & 0.074433 & 1.687500 & 0.066855 & 0.002817 \\
\hline Steroid receptor cofactor 1 & $\mathrm{C}$ & 55 & 2.213636 & 0.05596 & 2.004545 & 0.065420 & 0.016918 \\
\hline Glucocorticoid receptor interacting protein 1 & $\mathrm{C}$ & 54 & 0.546296 & 0.038479 & 0.291667 & 0.028634 & $3.1 \mathrm{E}-07$ \\
\hline Epidermal growth factor receptor & $\mathrm{D}$ & 58 & 0.939130 & 0.051644 & 1.017241 & 0.058130 & 0.319419 \\
\hline High-mobility group protein gene A2 & $\mathrm{D}$ & 55 & 0.786760 & 0.058145 & 0.212235 & 0.050288 & 0.007576 \\
\hline CD24 & $\mathrm{D}$ & 50 & 1.546447 & 0.037441 & 0.786955 & 0.039845 & $1.77 \mathrm{E}-05$ \\
\hline Ki-67 & $\mathrm{D}$ & 50 & 6.737374 & 0.908305 & 2.275510 & 0.231882 & $4.63 \mathrm{E}-06$ \\
\hline
\end{tabular}

\footnotetext{
${ }^{\mathrm{a}}$ Among total 60 cases, those cases with well-preserved cores for both myometrium and leiomyomata cores were counted.
} 
A
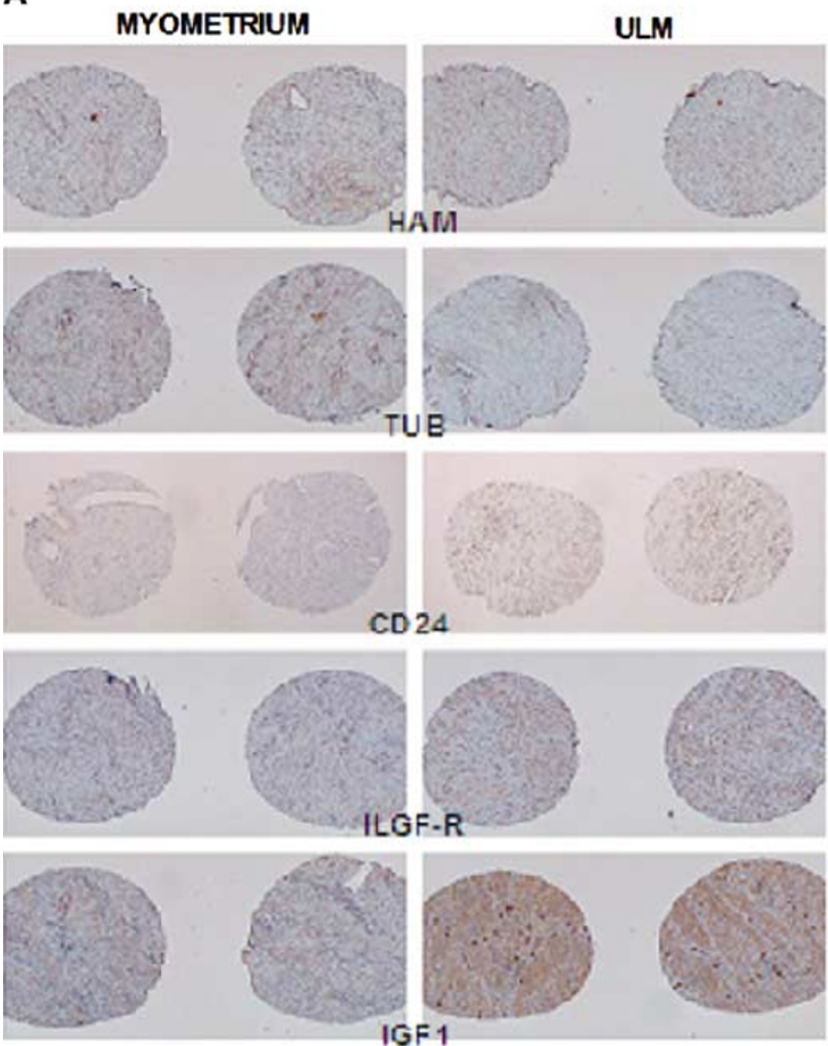
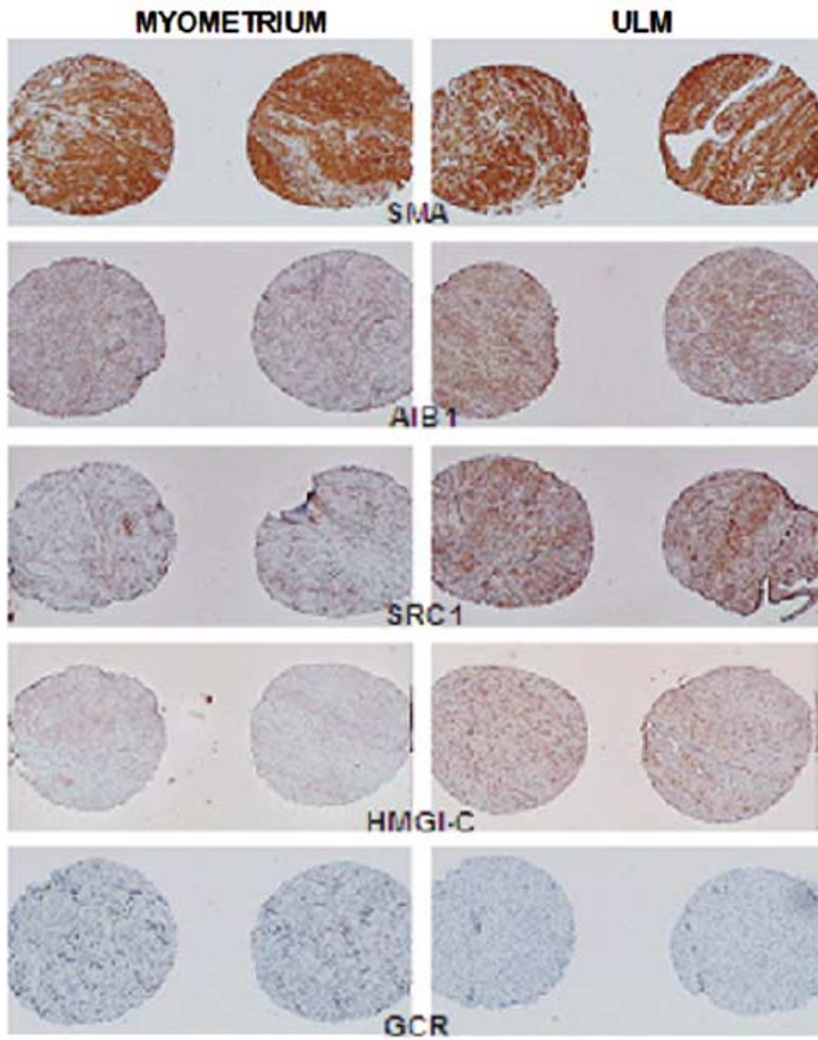

B

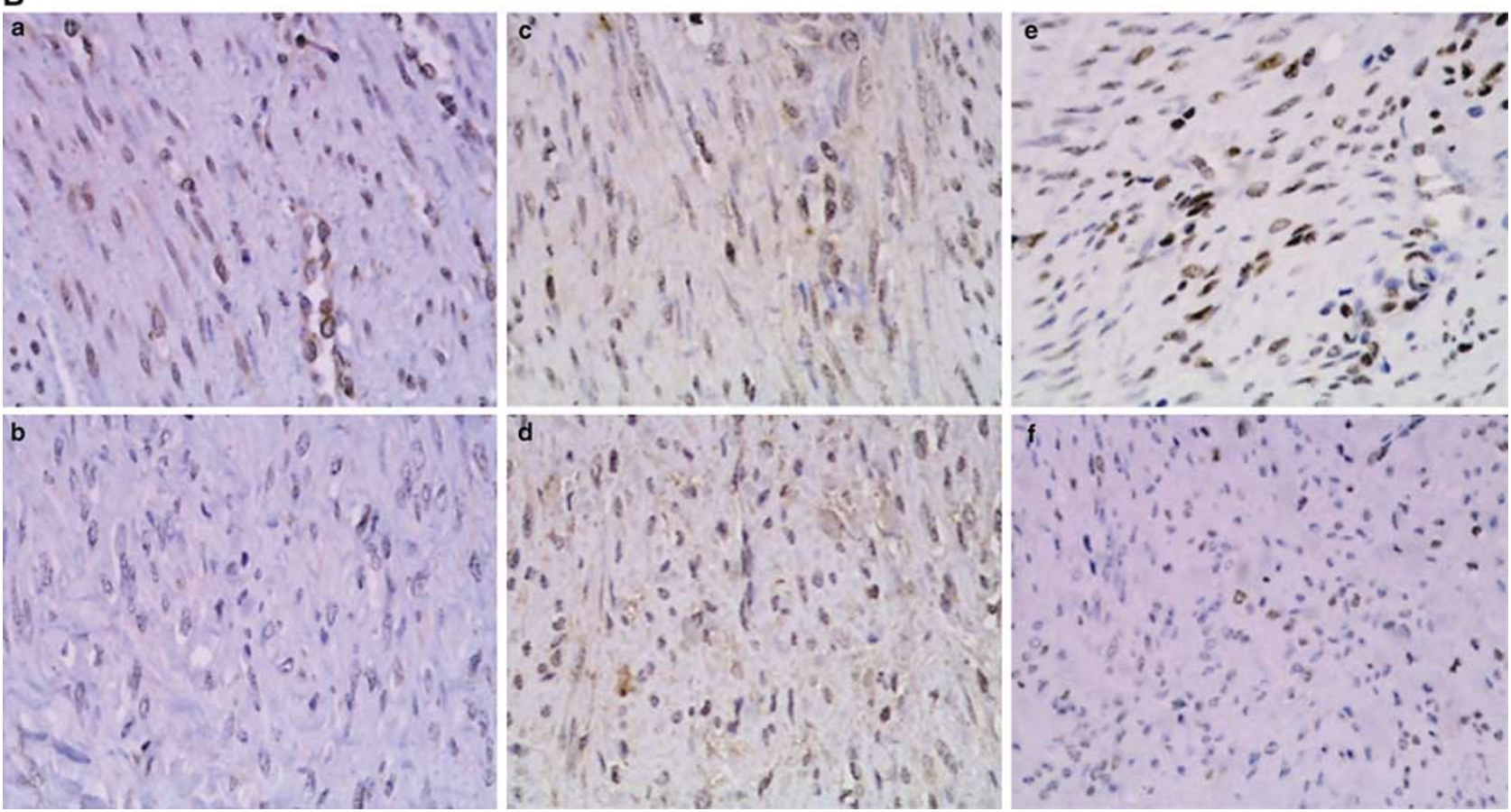

Figure 1 Part one: Some examples of immunohistochemical staining on tissue cores of microarray. Two normal myometrial tissue cores are on the left side and two uterine leiomyomata cores are on the right side. Immunomarkers are indicated: $\times 40$. Part two: Close view of immunostaining for tuberin (a and b), hamartin (c and $\mathbf{d})$ and glucocorticoid receptors (e and f) in normal myometrium (a, $\mathbf{c}$ and $\mathbf{e})$ and leiomyomata (b, $\mathbf{d}$ and $\mathbf{f}): \times 400$. 
STUM DCONT

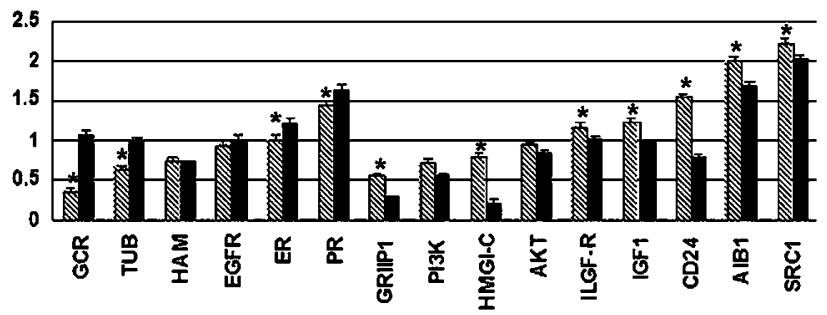

Figure 2 Differential expression of each marker between leiomyomas and myometrial controls by semiquantitative immunohistochemical analysis. Each bar represents the average immunoscore from normal myometrium (control, dark black) and leiomyomata (tumor, shadow). T thinner bars on top of each column are standard deviation. Stars indicate the statistical significance between control and tumor. Each marker is listed under the respective bar.

interactions between the insulin-signaling pathway and tuberin and hamartin. ${ }^{16,17}$ We tested some of the proteins in insulin-signaling pathway. The immunoreactivities for insulin-like growth factor 1 and insulin-like growth factor receptor were significantly higher in leiomyomata than in myometrium $(P<0.03$ and $<0.001)$, which is consistent with the previous studies. ${ }^{28,29}$ It has been shown that AKT and phosphatidylinositol 3-kinase were upregulated in fibroid. ${ }^{30}$ Our data showed a similar finding but statistically insignificant due to a large variation (Figure 2, Table 2). In general, the upregulation of these markers was presented in only a portion of leiomyomata ranging from 20 to $40 \%$ of leiomyomata (9-22 cases out of 52-55 cases). The patterns of up- or down-regulation of these proteins would result in a proliferative signal through the insulin pathway.

Panel C: Female steroid hormone receptors and their coactivators are expressed in different cells and in varying intensity in normal myometrium, depending on age and menstrual cycle stages. ${ }^{31}$ Therefore, a case controlled comparison was crucial. Overall, immunoreactivity for estrogen receptor and progesterone receptor decrease slightly in leiomyomata with range from 1.0 to 1.4 when compared with a range of 1.2-1.6 in the myometrium $(P<0.03)$. Glucocorticoid receptor showed a dramatic reduction of expression in most leiomyomata. The average immunoreactivity score for glucocorticoid receptor in leiomyomata was 0.36 , compared to $1.08(P<0.001)$ for myometrium (Figure 2, Table 2). The reduction of immunoreactivity for glucocorticoid receptor in leiomyomata was in both intensity and the percentage of positive cells. In contrast, the coactivators for the steroid receptors steroid receptor cofactor 1, glucocorticoid receptor interacting protein 1 and amplified in breast cancer 1 were moderately upregulated in about half of leiomyomata $(P<0.01)$. Steroid receptor cofactor 1 , glucocorticoid receptor interacting protein 1 and amplified in breast cancer 1, all showed nuclear staining. In addition, cytoplasmic staining was seen for glucocorticoid receptor interacting protein 1 and amplified in breast cancer 1 .

Panel D: High-mobility group protein gene A2 had been reported to be upregulated in some uterine leiomyomas. ${ }^{5,6}$ In our study, we examined highmobility group protein gene A2 in terms of its association with other proteins. Differential expression of high-mobility group protein gene A2 was noted in 26 out of 56 cases (46.4\%). Immunoreactivity for high-mobility group protein gene A2 is increased with a score of 0.79 in leiomyomata $v s$ 0.21 in myometrium $(P<0.01)$. CD24 is upregulated in more than half of the cases. The finding is consistent with the gene chip data from us (unpublished) and the other group. ${ }^{9}$ Smooth muscle actin was diffusely immunopositive in both myometrium and myomas. Immunoreactivity for epidermal growth factor receptor was slightly reduced in some leiomyomata, but the difference was not statistically significant. c-kit, cyclin D1 and Her2/neu are negative in most leiomyomata. p27 was immunopositive in some leiomyomata and myometrium and no difference is noted.

\section{Cluster Analysis}

The difference between myometrium and leiomyomata obtained by calculating the mean value was useful. It provided overall trends of either up- or downregulation of the individual gene products in leiomyomata. Considering the fact that the leiomyomata might not be homogeneous in its pathogenetic process, as well as the variations in tissue preparation, examination of individual tumor for the interested gene products could provide a way of separating them apart. To reach this object, we first calculated the net gain or loss of immunoscore for a specific immunomarker from each individual leiomyomata in comparison with matched myometrium (net value $=$ tumor immunoscore-myometrial immunoscore). Each net value gave positive or negative scores. The tissue microarray immunohistochemical scores were processed into precluster format using the TMA deconvoluter (for detail see Materials and methods). ${ }^{25,26}$ In an unsupervised cluster analysis, 15 immunomarkers presented two broad groups of up- or downregulation in 60 leiomyomata, centered on CD24 (upregulation) and glucocorticoid receptor (downregulation) (Figure 4a). An upregulation of the proteins from insulinsignaling pathway, sex steroid hormone cofactors, CD24 and HMGI appears to be confined to a group of about $40 \%$ patients (Figure 3a). In this group, downregulation of glucocorticoid receptor and tuberin is minimal. In contrast, above $50 \%$ leiomyomata showed a downregulation of glucocorticoid receptor and tuberin (Figure 3a). When we took into account the age as a factor of sex steroid hormone status, we found that the leiomyomata with the 
a

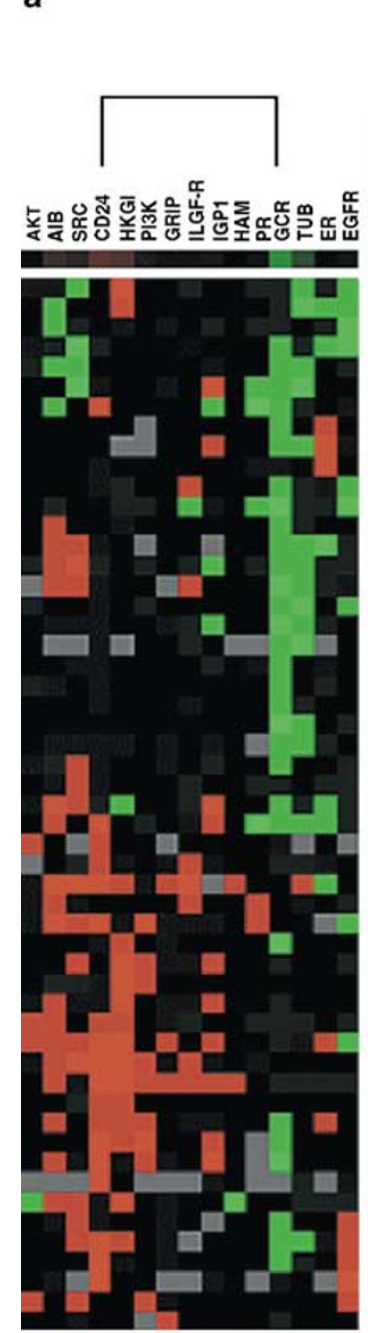

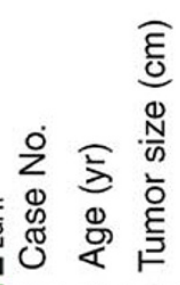

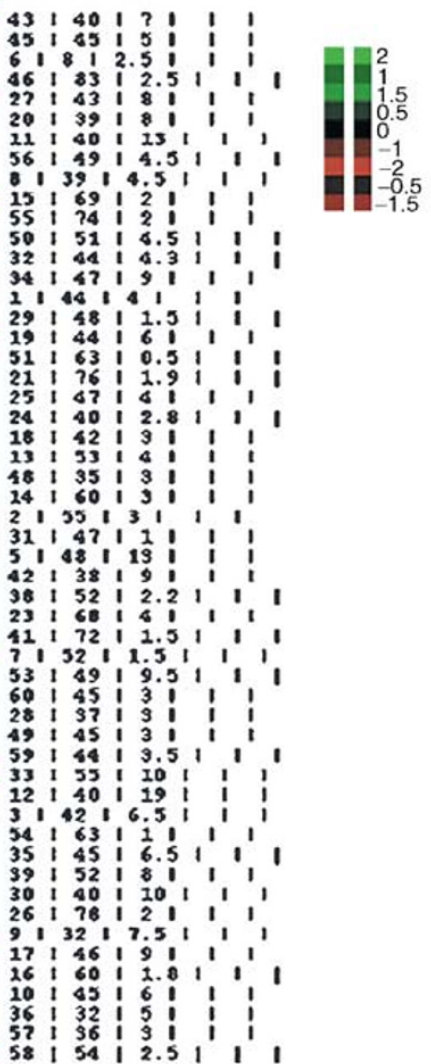

b

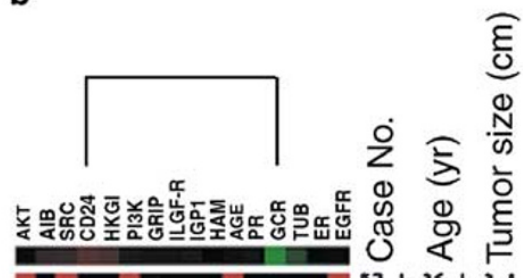

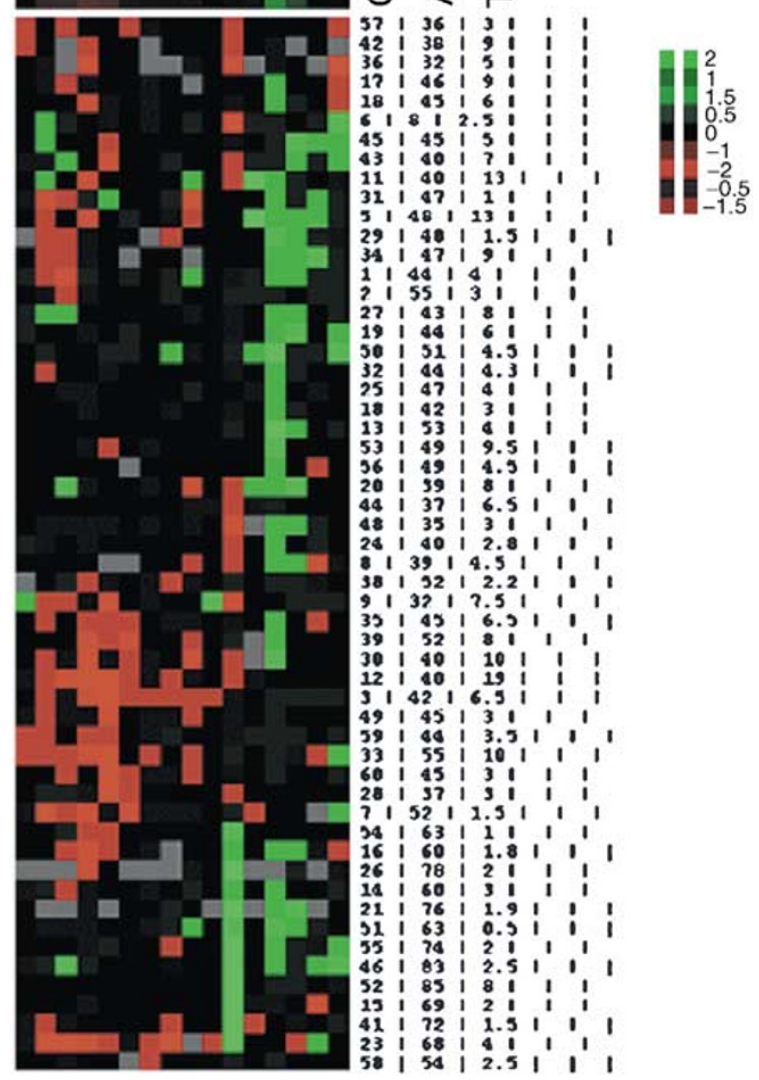

Figure 3 The dendrogram and hierarchichal cluster analysis of 15 immunomarkers in 60 cases with leiomyomata. The columns represent the immunomarkers and the rows are the leiomyomata. The case numbers, age and tumor size are listed on the right side. The immunoscores are indicated by green (downregulation), red (upregulation), black (no change) and gray (no data obtained). The levels of immunointensity are indicated on the right upper corners. (a) The dendrogram and cluster analysis centered on CD24 and glucocorticoid receptor. (b) The cluster analysis with age scores added (green: > 51 years; black: 46-50 years; red: < 40 years) (see Materials and methods for detail).

markers of an upregulation are mainly present in the age group of 40-50 years old and much less in that of the younger age and in postmenopausal women (Figure 3b). The distribution of downregulation of glucocorticoid receptor and tuberin appears to be less affected by age.

\section{Discussion}

Uterine leiomyomata are benign neoplasms composed of smooth muscle cells. Many efforts have been made to investigate their tumorigenesis. Data from recent studies indicate that leiomyomata are heterogeneous. Genetic defects from both human (rare familial aggregate) ${ }^{11}$ and animal model (Eker rats $)^{14}$ have been found to be linked with specific but different genes. Alteration of human mobility group protein genes caused by the gene translocation (chromosomal reciprocal translocations) are also considered candidate genes for leiomyomata. ${ }^{3,5}$

In this study, we evaluated the role of tuberin, insulin-signaling, steroid receptor cofactors as well as high-mobility group protein gene A2 in the leiomyomata. Based on the information obtained from animal model Eker rat ( $\mathrm{Tsc} 2^{\mathrm{Ek} /+}$ ), which carries one wild-type allele of the tuberous sclerosis gene 2 and one allele containing an inactivating viral insertion in intron 30, loss of tuberous sclerosis gene 2 is closely associated with the development of leiomyomata. In Eker rats, $50 \%$ of leiomyomata were found to have loss of the wild-type allele. Western analysis indicated that tuberin was highly expressed in the myometrium of normal Eker $\left(\mathrm{Tsc} 2^{\mathrm{Ek} /+}\right)$ and 

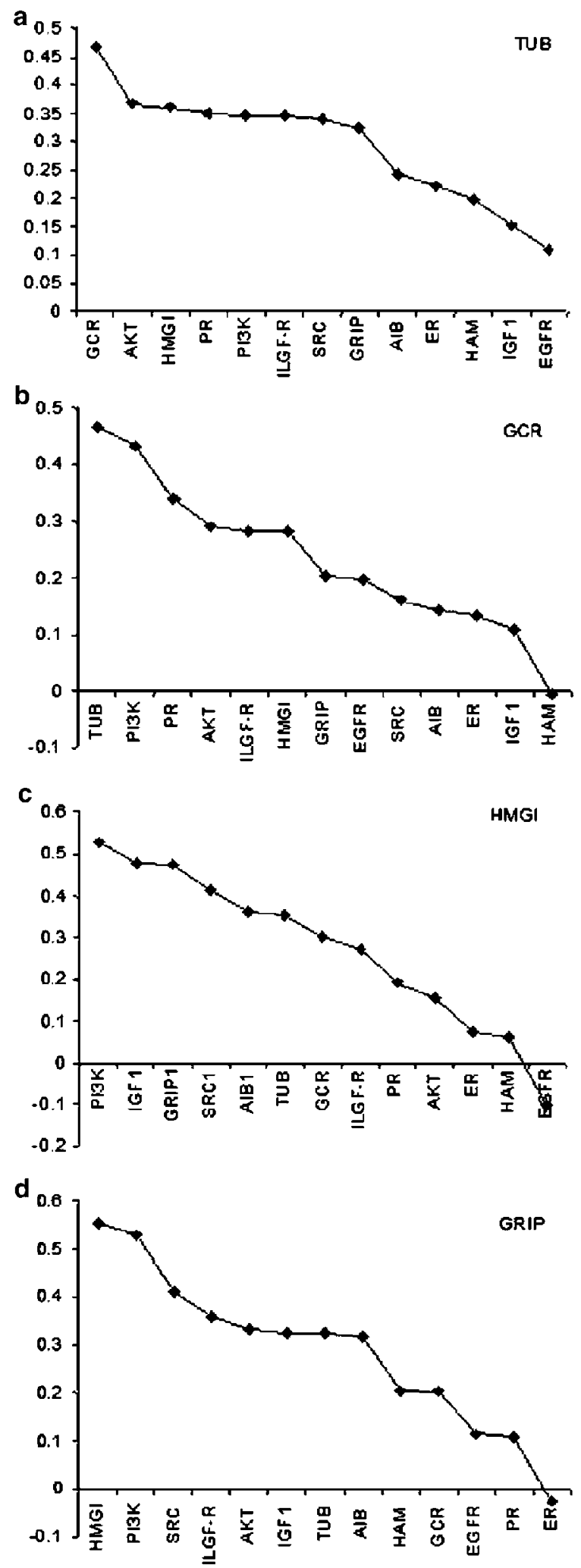

Figure 4 Correlations between tuberin (a), glucocorticoid receptor (b), high mobility group protein gene A2 (c) and glucocorticoid receptor interacting protein 1 (d) expression and other immunomarkers. The correlation rate from 0 to 0.6 is on the $y$-axis and the correlated markers are on the $x$-axis. wild-type (Tsc $2^{+/+}$) rats. ${ }^{14}$ Expression was observed in myometrium from both young animals throughout the estrus cycle from animals in reproductive senescence (16 months old), suggesting that ovarian hormone levels do not regulate expression. ${ }^{14}$ In contrast to aged-matched (16-month) normal myometrium, virtually all ${ }^{12}$ of the leiomyomata samples demonstrated absent or greatly diminished tuberin expression.

In our study, $53 \%$ of leiomyomata showed either absent (9/54) or reduced (19/54) immunoreactivity for tuberin compared with the normal myometrium $(P<0.001)$. In contrast, there was no change of hamartin between myometrium and leiomyomata. These findings are compatible with the animal study, in which, only loss of tuberin is associated with leiomyomata. What causes an absent or diminished expression of tuberin in human leiomyomata is not known. It would be useful to look for a molecular alteration of tuberin by testing a loss of heterozygosity or molecular identification of messenger RNA (mRNA) levels of tuberin in leiomyomata. Considering only half of cases showed the changes of tuberin in leiomyomata, an epigenetic modification of tuberin might exist. A strong correlation of tuberin with glucocorticoid receptor was noted (Figures 3b and 4a,b). Tuberin contains a domain that interacts with steroid receptor families, especially with glucocorticoid receptor, to form a complex. ${ }^{32}$ This complex is a negative regulator of the transcriptional activity of glucocorticoid receptor. Expression of glucocorticoid receptor in uterus is basically unknown until a recent study from rat uterus showed moderate expression of glucocorticoid receptor in normal endometrium and smooth muscle of the myometrium. ${ }^{33}$ In our previous study, we had found a parallel reduction of glucocorticoid receptor and tuberin in human fundic gastric polyps (FGPs). ${ }^{34}$ A gene chip study also showed dramatically reduced glucocorticoid receptor mRNA in leiomyomata compared with normal myometrium. ${ }^{10}$ Glucocorticoid receptor is known to be a general response to stress and inflammation. Particularly, it suppresses expression of fibronectin and laminin in uterus. ${ }^{35}$ As glucocorticoid receptor is complementary to estrogen receptor and progesterone receptor in endometrium, ${ }^{33}$ and loss of glucocorticoid receptor in leiomyomata may be a fundamental factor for the loss of negative regulation of the cell proliferation and for promoting the fibrotic background in leiomyomata. Insulin-signaling pathway is one of major routes in regulating the functional status of tuberin through an activated AKT kinase. ${ }^{27,36}$ The latter can inactivate tuberin by phosphorylation of tuberin. To that end, we examined some key proteins in the insulin-signaling pathway. We found an upregulation of insulin-like growth factor 1, insulin-like growth factor receptor, AKT kinase and phosphatidylinositol 3-kinase in $20-40 \%$ of cases leiomyomata (Figure 3). Our results as well as published data ${ }^{29,30,37}$ provide an evidence of 
increased activity of the insulin pathway in leiomyomata. However, there is a weak association between alteration of tuberin and the activity of the insulin-signaling pathway (Figures 3a and 4a).

To our knowledge, expression of the steroid hormone receptor cofactors in normal leiomyomata has not been reported. These cofactors were found to be expressed at high levels in normal myometrium. In our study, we found a moderate upregulation of these cofactors in leiomyomata. The increased level of expression of the cofactors appears to be not associated with increased level of estrogen receptor and progesterone receptor (Figures 3 and $4 \mathrm{~d}$ ). Interestingly, we have found a linkage of upregulation of three steroid receptor cofactor with an upregulation of high-mobility group protein gene A2 (Figures 3 and 4c). Out of 56 leiomyomata, 26 $(46.4 \%)$ show increased immunoreactivity for highmobility group protein gene A2. High mobility group proteins are abundant, heterogeneous, nonhistone components of chromatin. They bind in the minor groove of DNA and it has been suggested to be a transcription factor. ${ }^{6,38,39}$ The causal relation between changes in these high mobility group protein genes and aberrant growth control in benign tumors remains to be established. ${ }^{3}$ Tallini et $a l^{5}$ found that about $36 \%(9 / 25)$ of leiomyomata presented chromosomal alteration involving chromosome 12, near high-mobility group protein gene A2 locus. Those cases with altered chromosome 12 showed an upregulation of high-mobility group protein gene A2 in $50 \%$ of cases. The finding was also supported from another study. ${ }^{6}$ Our data of expression of high mobility group protein A2 in a relative large sampling (60 cases) are compatible with results mentioned above.

With the aid of cluster analysis and Eisen's TREEVIEW software, ${ }^{25,26}$ the express profile of these potential tumorigenetic factors in 60 leiomyomata can be further classified into two broad groups. One presents a higher activity of insulin-signaling pathway, sex steroid receptor cofactors, CD24 and highmobility group protein gene A2. The other one is associated with downregulation of tuberin and glucocorticoid receptor (Figure 3a). The first group is likely found in the women in middle forties (Figure 3b). On the contrary, the alteration of glucocorticoid receptor and tuberin are distributed in all age groups.

In summary, we have examined expression of four different functional groups of genes in a moderate sample size of human leiomyomata. With the advantage of tissue microarray, internal myometrial controls and immunocontrols, we highlight the general trends of expression pattern of some potential tumorigenic factors in leiomyomata. We have shown two broad groups of leiomyomata: one group is associated with alteration of tuberin and glucocorticoid receptor, and the other one is associated with alteration of high-mobility group protein gene A2, insulin-signaling and steroid receptor cofactors.

\section{Acknowledgements}

We are very grateful to Dr Jonathan Melamed for his assistance in preparation of tissue microarray. This work was partially presented at the 2004 National Meeting of United States and Canadian Academy of Pathology in Vancouver, Canada.

\section{References}

1 Flake GP, Andersen J, Dixon D. Etiology and pathogenesis of uterine leiomyomas: a review. Environ Health Perspect 2003;111:1037-1054.

2 Dixon D, He H, Haseman JK. Immunohistochemical localization of growth factors and their receptors in uterine leiomyomas and matched myometrium. Environ Health Perspect 2000;108(Suppl 5):795-802.

3 Van de Ven WJ. Genetic basis of uterine leiomyoma: involvement of high mobility group protein genes. Eur J Obstet Gynecol Reprod Biol 1998;81:289-293.

4 Nibert M, Heim S. Uterine leiomyoma cytogenetics. Genes Chromosomes Cancer 1990;2:3-13.

5 Tallini G, Vanni R, Manfioletti G, et al. High-mobility group protein gene A2 and HMGI(Y) immunoreactivity correlates with cytogenetic abnormalities in lipomas, pulmonary chondroid hamartomas, endometrial polyps, and uterine leiomyomas and is compatible with rearrangement of the high-mobility group protein gene A2 and HMGI(Y) genes. Lab Invest 2000;80: 359-369.

6 Klotzbucher M, Wasserfall A, Fuhrmann U. Misexpression of wild-type and truncated isoforms of the highmobility group I proteins high-mobility group protein gene A2 and HMGI(Y) in uterine leiomyomas. Am J Pathol 1999;155:1535-1542.

7 Quade BJ, Weremowicz S, Neskey DM, et al. Fusion transcripts involving HMGA2 are not a common molecular mechanism in uterine leiomyomata with rearrangements in 12q15. Cancer Res 2003;63: 1351-1358.

8 Skubitz KM, Skubitz AP. Differential gene expression in leiomyosarcoma. Cancer 2003;98:1029-1038.

9 Catherino WH, Prupas C, Tsibris JC, et al. Strategy for elucidating differentially expressed genes in leiomyomata identified by microarray technology. Fertil Steril 2003;80:282-290.

10 Tsibris JC, Segars J, Coppola D, et al. Insights from gene arrays on the development and growth regulation of uterine leiomyomata. Fertil Steril 2002;78:114-121.

11 Tomlinson IP, Alam NA, Rowan AJ, et al. Germline mutations in fumarate hydratase predispose to dominantly inherited uterine fibroids, skin leiomyomata and papillary renal cell cancer. Nat Genet 2002;30: 406-410.

12 Everitt JI, Goldsworthy TL, Wolf DC, et al. Hereditary renal cell carcinoma in the Eker rat: a unique animal model for the study of cancer susceptibility. Toxicol Lett 1995;82-83:621-625.

13 Burroughs KD, Howe SR, Okubo Y, et al. Dysregulation of IGF-I signaling in uterine leiomyoma. J Endocrinol 2002;172:83-93.

14 Hunter DS, Klotzbucher M, Kugoh H, et al. Aberrant expression of HMGA2 in uterine leiomyoma associated with loss of tuberous sclerosis gene 2 tumor suppressor gene function. Cancer Res 2002;62:3766-3772. 
15 Wei J, Li P, Chiriboga L, et al. Tuberous sclerosis in a 19-week fetus: immunohistochemical and molecular study of hamartin and tuberin. Pediatr Dev Pathol 2002;5:448-464.

16 Gao X, Pan D. Tuberous sclerosis gene 1 and tuberous sclerosis gene 2 tumor suppressors antagonize insulin signaling in cell growth. Genes Dev 2001;15: 1383-1392.

17 Montagne J, Radimerski T, Thomas G. Insulin signaling: lessons from the Drosophila tuberous sclerosis complex, a tumor suppressor. Sci STKE 2001;2001: PE36.

18 Parry L, Maynard JH, Patel A, et al. Molecular analysis of the tuberous sclerosis gene 1 and tuberous sclerosis gene 2 tumour suppressor genes in sporadic glial and glioneuronal tumours. Hum Genet 2000;107:350-356.

19 Smolarek TA, Wessner LL, McCormack FX, et al. Evidence that lymphangiomyomatosis is caused by tuberous sclerosis gene 2 mutations: chromosome 16 p13 loss of heterozygosity in angiomyolipomas and lymph nodes from women with lymphangiomyomatosis. Am J Hum Genet 1998;62:810-815.

$20 \mathrm{Yu}$ J, Astrinidis A, Henske EP. Chromosome 16 loss of heterozygosity in tuberous sclerosis and sporadic lymphangiomyomatosis. Am J Respir Crit Care Med 2001;164:1537-1540.

21 Mizuguchi M, Kato M, Yamanouchi H, et al. Loss of tuberin from cerebral tissues with tuberous sclerosis and astrocytoma. Ann Neurol 1996;40:941-944.

22 Mizuguchi M, Ikeda K, Takashima S. Simultaneous loss of hamartin and tuberin from the cerebrum, kidney and heart with tuberous sclerosis. Acta Neuropathol 2000;99:503-510.

23 Mizuguchi M, Kato M, Yamanouchi H, et al. Tuberin immunohistochemistry in brain, kidneys and heart with or without tuberous sclerosis. Acta Neuropathol 1997;94:525-531.

24 Nisolle M, Casanas-Roux F, Marbaix E, et al. Transplantation of cultured explants of human endometrium into nude mice. Hum Reprod 2000;15:572-577.

25 Eisen MB, Spellman PT, Brown PO, et al. Cluster analysis and display of genome-wide expression patterns. Proc Natl Acad Sci USA 1998;95:14863-14868.

26 Liu CL, Prapong W, Natkunam Y, et al. Software tools for high-throughput analysis and archiving of immunohistochemistry staining data obtained with tissue microarrays. Am J Pathol 2002;161:1557-1565.

27 Potter CJ, Pedraza LG, Xu T. Akt regulates growth by directly phosphorylating Tsc2. Nat Cell Biol 2002;4: 658-665.
28 Englund K, Lindblom B, Carlstrom K, et al. Gene expression and tissue concentrations of IGF-I in human myometrium and fibroids under different hormonal conditions. Mol Hum Reprod 2000;6: 915-920.

29 Giudice LC, Irwin JC, Dsupin BA, et al. Insulin-like growth factor (IGF), IGF binding protein (IGFBP), and IGF receptor gene expression and IGFBP synthesis in human uterine leiomyomata. Hum Reprod 1993;8: 1796-1806.

30 Kovacs KA, Lengyel F, Kornyei JL, et al. Differential expression of Akt/protein kinase B, Bcl-2 and Bax proteins in human leiomyoma and myometrium. J Steroid Biochem Mol Biol 2003;87:233-240.

31 Shiozawa T, Shih HC, Miyamoto T, et al. Cyclic changes in the expression of steroid receptor coactivators and corepressors in the normal human endometrium. J Clin Endocrinol Metab 2003;88:871-878.

32 Henry KW, Yuan X, Koszewski NJ, et al. Tuberous sclerosis gene 2 product modulates transcription mediated by steroid hormone receptor family members. J Biol Chem 1998;273:20535-20539.

33 Korgun ET, Dohr G, Desoye G, et al. Expression of insulin, insulin-like growth factor I and glucocorticoid receptor in rat uterus and embryo during decidualization, implantation and organogenesis. Reproduction 2003;125:75-84.

34 Wei J, Chiriboga L, Yee $\mathrm{H}$, et al. Altered cellular distribution of tuberin and glucocorticoid receptor in sporadic fundic gland polyps. Mod Pathol 2002; 15:862-869.

35 Guller S, Markiewicz L, Wozniak R, et al. Developmental regulation of glucocorticoid-mediated effects on extracellular matrix protein expression in the human placenta. Endocrinology 1994;134: 2064-2071.

36 Inoki K, Li Y, Zhu T, et al. Tuberous sclerosis gene 2 is phosphorylated and inhibited by Akt and suppresses mTOR signalling. Nat Cell Biol 2002;4:648-657.

37 Gao Z, Matsuo H, Wang Y, et al. Upregulation by IGF-I of proliferating cell nuclear antigen and Bcl-2 protein expression in human uterine leiomyoma cells. J Clin Endocrinol Metab 2001;86:5593-5599.

38 Hisaoka M, Sheng WQ, Tanaka A, et al. HMGIC alterations in smooth muscle tumors of soft tissues and other sites. Cancer Genet Cytogenet 2002;138: 50-55.

39 Tallini G, Dal Cin P. HMGI(Y) and high-mobility group protein gene A2 dysregulation: a common occurrence in human tumors. Adv Anat Pathol 1999;6:237-246. 